\title{
A epistemologia científica que subjaz aos estudos da linguagem no âmbito do Interacionismo Sociodiscursivo
}

The scientific epistemology underpinning language studies within the sociodiscursive interactionism perspective

\author{
Raquel BAsílıO (UFPB) \\ Regina Celi Mendes Pereira (UFPB) \\ Renata de Lourdes Costa de Menezes (UFPB)
}

\section{RESUMO}

Inseridas nas discussões desenvolvidas no contexto do projeto Ateliê de Textos Acadêmicos (ATA) no qual analisamos aspectos linguísticodiscursivos de textos acadêmicos em diversos campos de produção do conhecimento, confrontamo-nos com a necessidade de refletir sobre epistemologia e metodologia cientifica. Objetivamos, portanto, discutir sobre a constituição do conceito de ciência instituído no cerne do Interacionismo Sociodiscursivo (ISD) a partir do aparato conceitual e metodológico empregado por Bronckart $(1999,2006,2008)$ para a abordagem e descrição dos fatos de linguagem, de natureza eminentemente sócio-histórico-cultural. Para tanto, assentaremos nossas discussões nos estudos referentes ao saber/fazer cientifico, em especial nas obras de Popper (2007 [1934]) e Bourdieu (1983, 2002, 2004). As reflexões apontam que, no processo de construção do conhecimento, o pesquisador deve evitar a submissão a um padrão metodológico dominante, dogmático e autoritário, e estar aberto às várias abordagens disponiveis.

Palavras-chave: epistemologia cientifica; construção; conhecimento; ISD. 


\section{ABSTRACT}

Due to the discussions and research carried out in the context of the project called Ateliê de Textos Acadêmicos - ATA (Academic Texts Workshop - ATW), within which we analyze academic texts produced in different branches of knowledge, concerning their linguistic-discursive aspects, we have been faced with the need to reflect on epistemology and scientific methodology. Therefore, our main aim is to discuss the construction of the concept of science within the Sociodiscursive Interactionism (SDI) perspective, considering the conceptual and methodological framework used by Bronckart $(1999,2006,2008)$ to approach and describe language facts, considered as being of a socio-historical-cultural nature. In order to do so, we will refer to studies on scientific know-how, especially the work by Popper (2007 [1934]) and Bourdieu (1983, 2002, 2004). The results indicate that the researcher, in the process of knowledge construction, should be open to the many approaches available and not just follow a dominant, dogmatic and authoritarian methodological standard.

Key-words: scientific epistemology; construction; knowledge; SDI.

\section{Introdução}

Esse estudo é fruto das discussões realizadas no âmbito do projeto "Ateliê de Textos Acadêmicos" (ATA/PNPD"), desenvolvido no Programa de Pós-Graduação em Linguística da Universidade Federal da Paraíba (PROLING/UFPB), no contexto das pesquisas em Linguística Aplicada (LA), orientado pelos princípios teóricos e metodológicos do Interacionismo Sociodiscursivo (ISD).

O projeto ATA opera na análise dos aspectos linguístico-discursivos de textos acadêmicos e na didatização da escrita no interior dos diversos campos de produção do conhecimento. Esses dois eixos de atuação, por sua vez, incitaram a reflexão sobre o que é ciência, quais as ideologias cientificistas que guiam as pesquisas nos diferentes campos do saber, como essas questões encontram-se materializadas nos textos escritos e, por fim, o que fundamentalmente interessa nesse artigo, qual a epistemologia científica que subjaz ao quadro geral do ISD, enquanto 
corrente amplamente arraigada à LA e enquanto arcabouço teóricometodológico de nossas pesquisas nos estudos da linguagem.

Nossa intenção, portanto, é discutir sobre a constituição do conceito de ciência instituído no cerne do ISD a partir das ideias e métodos empregados por Bronckart $(1999,2006,2008)$ para a abordagem e descrição dos fatos de linguagem, de natureza eminentemente sóciohistórico-cultural. Para tanto, assentaremos nossas discussões nos estudos referentes à compreensão do saber/fazer científico, conforme seu desenvolvimento no decorrer da história da atividade científica e, em especial, no contraponto conceitual das obras de Popper (2007 [1934]) e Bourdieu (1983, 2002, 2004).

Iniciaremos, assim, apresentando, brevemente, o percurso histórico da ciência, a partir dos temas, objetos e métodos socialmente legitimados nesse domínio ao longo do tempo e, em seguida, discutiremos as implicações dos paradigmas científicos vigentes para a constituição do corpo teórico e metodológico do ISD, notadamente seus efeitos para a compreensão do conceito de língua, texto e linguagem humana, bem como seus reflexos nas pesquisas filiadas a esse quadro.

\section{O percurso histórico da ciência}

O curso da "História da Ciência" tem sido conduzido, conforme Chalmers (1993), pela questão primordial: o que é um fato científico? Esse fenômeno, então, foi definido de maneiras diferentes, ao longo do tempo, pelos inúmeros pesquisadores que se lançaram na tarefa de refletir sobre ele. Pautar-nos-emos, a seguir, na historiografia realizada por Scruton (2008) para levantar esse panorama da construção do discurso científico, cientes da impossibilidade de apresentar um quadro completo nos limites dessa seção. Faremos, nesse caso, um resumo de algumas das principais obras que, ao longo da história da humanidade, teceram o conceito de ciência, com o fim de problematizá-lo nas análises posteriores que apresentaremos.

Antes de qualquer inclinação científica, o pensamento religioso acompanha a humanidade desde seus primórdios (Araújo 2006). A doutrina teológica pressupõe um sujeito que a tudo conhece e tudo sabe, haja vista que os objetos já se apresentam para ele explicados e 
interpretados pelas proposições sagradas. Nesse sentido, não lhe carece produzir verdades sobre o mundo ou falsear o conhecimento, ante sua fé cristã na transcendência.

Contrariando, pois, a autoridade escolástica vigente, em 1620,Francis Bacon publicou a polêmica obra Instauratio Magna - Grande Instauração ou Grande Renovação. Trata-se de um livro constituído de um "Proêmio", uma "Epistola dedicatória", um "Prefácio", um "Plano de trabalho" e duas seções, o Livro I e o Livro II. O Novum Organum, Esboço de uma história natural e experimental, que faz parte do Livro II da Instauratio Magna, consolidou a busca por um método preditivo, de descrição e compreensão da realidade, que definiria o conhecimento científico. Assim, segundo Brandão (2010), o mundo natural deixava de ser o portador dos misteriosos desígnios de Deus para se tornar o próprio objeto de investigação pelos sentidos.

Bacon criticava, portanto, ao mesmo tempo, o método aristotélico, baseado no silogismo, e seu modo de conceber a relação do homem com a natureza, e o antropocentrismo aristotélico que situava o homem no centro do mundo e, logo, posicionava o conhecimento humano na razão, na inteligibilidade a priori, e não na experiência. O Novum Organum, por sua vez, alvitrava a capacidade humana de compreensão sensitiva da realidade e o poder do homem sobre a natureza. Dessa maneira, propunha aos seus leitores que o conhecimento só poderia ser verdadeiramente científico se adviesse da observação e se adotasse a postulação de leis universais sobre as instâncias observadas (Bacon2014 [1620]).

Nessa perspectiva, segundo refere Scruton (2008:180), "o conhecimento científico é a posteriori: ele surge da efetiva experiência, e se baseia nela. A ciência não trata de verdades necessárias, mas de questões factuais contingentes". Em outras palavras, Bacon afirmava que deveria se optar pelo pensamento indutivo, pois o conhecimento científico se constrói na universalização dos fatos estabelecidos pela observação e experiência. Ele acreditava, então, com essa proposta, estar lançando a base para uma união entre as faculdades empíricas e racionais. E suas concepções, sem dúvida, têm um impacto importante para delimitação do campo científico. 
Outra das noções mais influentes de Bacon se refere a sua afirmação de que a ciência deve visar à abstração, o que, por sua vez, só seria alcançada por meio de teorias expressas em termos quantitativos e não qualitativos. Seu argumento baseava-se na ideia de que, entre as formas naturais, a quantidade é a mais abstrata e separável da matéria física, conduzindo um levantamento com poucas chances de distorção. A partir de então, tudo deveria ser explicado em termos matemáticos (Bacon 2014 [1620]).

Devemos sublinhar, entretanto, que há diferentes posturas diante da obra de Bacon e que nós apresentamos, nesse espaço, apenas uma das possíveis leituras. Seus intérpretes, em cada escola e em cada época, constroem leituras diversas e, algumas vezes, opostas, sobre as questões que Bacon deixou impressas. Um dos motivos reside, talvez, no fato do livro ser escrito em aforismo. Tal escolha, segundo o autor, deve-se a sua postura diante da busca do conhecimento. Sobre seu estilo aforístico, ele diz: "por apresentar um conhecimento inacabado, convida a continuar pesquisando" (Bacon2014 [1620]:405).

Um exemplo das leituras contraditórias permitidas pelo texto de Bacon é sobre a relação do pesquisador com seu objeto de pesquisa. Ao mesmo tempo em que ele afirma que "o processo de construção de conhecimento é dirigido por leis mecânicas" (Bacon 2014 [1620]:97), ele afirma também que "o processo de construção de conhecimento é realizado sem regras - só com o voo livre da mente humana" (Bacon 2014 [1620]:103). Para aqueles que estão envolvidos com a pesquisa cientifica atualmente, a contradição expressa por Bacon encarna a contradição existente na ciência nos nossos dias. Evidentemente, a primeira frase foi extremamente fecunda no campo das ciências naturais e exatas, pois, subjacente a esta relação entre o pesquisador e seu objeto de pesquisa, temos uma afirmação acerca do método indutivo empirista.

A reflexão de Bacon sobre o método científico e o trabalho do cientista reafirma e confere autoridade à concepção de ciência calcada num procedimento experimental, conforme apresentada ao mundo ocidental a partir das formulações de Galileu Galilei publicadas na obra Sidereus Nuncius (1610). Essa obra foi alvo de críticas severas por parte das leis religiosas da época, contudo, por outro lado, com sua publicação, 
as ideias de Bacon ganharam a permissão e aprovação do Rei James I. Esse fato permitiu que o método experimental conquistasse mais adeptos e defensores.

Muitos são de acordo ao afirmar que Galilei causou uma ruptura no modo de construir conhecimento, instituindo, na história da humanidade, uma atitude empírica na pesquisa científica. O que favoreceu a ocorrência desse corte não foram necessariamente as observações e experiências que ele empreendeu, mas sua atitude em relação ao conhecimento. Para ele, o mais importante era aceitar que não devemos optar por teorias pré-existentes, pois os fatos é que deveriam apontar os caminhos de construção do saber. Porém, cabe ressaltar, sua obra só teve o impacto devido após a publicação do Novo Organon.

No século XVI, portanto, a comunidade científica da época, que incluía René Descartes, aceitava plenamente que a experiência era a base do conhecimento científico. Descartes, porém, apresentou algo novo. Ele afirmou que só a razão fundamenta a verdade e, nesse sentido, induziu à compreensão de que há uma subjetividade cognoscente, ao mesmo tempo em que há uma objetividade cognoscível, estabelecendo, pois, a existência de um sujeito que ordena o conhecimento (Brandão 2010).Ele, segundo Bronckart et al.(1996), introduziu a ideia de ser humano consciente e sustentou que todas as produções humanas seriam derivadas desse poder original que se chama consciência.

O conhecimento, então, passou a ser o resultado da apreensão de verdades (capturadas por intermédio dos sentidos e do raciocínio e organizadas de forma metodológica) por um sujeito sobre um objeto. A partir desses apontamentos, em 1637, René de Descartes lança sua obra Discurso do Método, na qual defenderá o método dedutivo. À luz da dedução, para entender um fenômeno, basta compreender suas partes. As experiências, então, delineariam os princípios gerais, frutos da razão.

No cerne da revolução científica, e na sua esteira, Newton publica Philosophiae naturalis principia mathematica (1687), que conferiu ao pensamento da época uma completa demonstração do método experimental, abrindo as portas para várias obras científicas de cunho empirista, forjando assim o que entendemos atualmente com o termo "Ciência Moderna". 
Imbuído dessa noção empirista de ciência construída sóciohistoricamente, Chalmers (1993) conclui que os fatos científicos são afirmações sobre o mundo que podem ser diretamente estabelecidas por meio do manuseio cuidadoso, neutro e sistemático dos dados da realidade. Isso significa que a ciência deve se fundamentar no que podemos ver, ouvir, tocar e nunca deve se basear em opiniões pessoais ou especulações. Os fatos científicos, por sua vez, devem levar à construção de leis e teorias que constituem o "conhecimento científico objetivo". Tal conceito de ciência evocado por Chalmers, também tem origem nas obras de Auguste Comte, intituladas: Système de philosophie positive (1830-1842), Cathéchisme positiviste (1852), Système de politique positive (1851-1854), Appel aux conservateurs (1855) e Synthèse subjective (1856).

Sobre a reflexão de Comte e o método positivista, não podemos ignorar que há atualmente várias correntes denominadas "positivistas", o que confere a este título uma abrangência semântica importante. Por essa razão, exige-se cautela ao definir o termo. Partimos, então, da concepção restrita à época em que as obras foram publicadas sem traçar paralelos com as disciplinas atuais. Desse modo, sobre o método positivista, podemos afirmar que consistia na busca por leis gerais que regem os fenômenos naturais por meio da observação e da aplicação de experimentos observáveis. O positivismo de Comte consiste numa reação ao transcendentalismo idealista alemão e ao romantismo, que davam grande importância aos afetos individuais e coletivos e à subjetividade. Segundo ele, problemas de natureza metafísica, e não científica (Bronckart et al. 1996). Comte, pois, acreditava na necessidade de limitarmos nossa busca por conhecimento à experiência humana, ao mundo sensível e ao conhecimento aos fatos observáveis.

Posteriormente, Comte, em sua obra Système de politique positive (1851-1854), defende a aplicação do método positivista nas ciências sociais. Esta posição, em especial, foi alvo de muitas críticas ao longo do tempo, originada de diferentes campos do saber. Temas como a importância da afetividade e da subjetividade para o ser humano em geral e para a prática científica em particular, da inclusão do social e do relativismo positivista, discutidos a partir da obra de Comte, constituem temas fecundos e de grande impacto na comunidade científica atual (cf.: Lacerda 2009). 
Entre os anos de 1929 a 1938 diversos estudiosos, filósofos e cientistas, unem-se na Universidade de Viena em torno da defesa de uma tradição empirista. O "Circulo de Viena", ou os "neopositivistas", como ficaram conhecidos os seus membros, tornou-se o mais importante movimento filosófico do início do século XX. A publicação do manifesto A concepção cientifica do mundo (1929) atraiu estudiosos das mais diversas áreas do conhecimento, com a intenção de discutir sobre a realização de uma unidade da ciência, ou seja, sobre a possibilidade de todas as ciências adotarem o mesmo método, um método legitimamente científico.

Uma das consequências mais importantes do Círculo de Viena repousa na proposta de abolir a distinção entre as ciências da natureza e as ciências humanas, e de adotar a distinção entre ciências empíricas e ciências analíticas. Em geral, a unificação das ciências levaria, aos olhos de Carnap, - um de seus membros mais destacados -, ao "empirismo", já que todo conhecimento não analítico é oriundo da experiência; e ao "logicismo", em vez que toda a ciência deve se submeter a uma análise lógica.

A importância das ideias desenvolvidas em Viena no período entre as duas Grandes Guerras pode ser sentida em seus prolongamentos. Teóricos, dentre eles Karl Popper, desenvolveram suas posições teórico-filosóficas a partir de duras críticas ao método neopositivista ou, também denominado, positivismo lógico.

Popper, por volta dos anos de 1926, frequentou os seminários ministrados por Carnap na Universidade de Viena e, em 1934, publicou sua primeira obra, A lógica da descoberta cientifica, assumidamente um diálogo com as ideias do Círculo de Viena. Nessa obra, segundo Quelbani (2009 [1953]:127), Popper "demonstra que a tarefa da lógica consiste em submeter o método científico a uma análise lógica, que permite verificar um sistema de enunciados". A tese central de Popper é a de que toda descoberta científica deve sobreviver ao critério de demarcação entre o científico e o não científico, em outras palavras, o enunciado verdadeiramente científico deve ser objetivo e não subjetivo. Tal critério foi chamado de "princípio da falseabilidade", um preceito de verificação de qualquer enunciado pretensamente científico (Popper 2007 [1934]). Para ele, toda teoria é falsificável e, por essa razão, pode ser refutada como falsa ou aceita como verdadeira. 
Concordamos com a leitura que Quelbani (2009 [1953]:135) faz do debate entre Popper e Carnap, quando afirma que

se o projeto neopositivista era justificar as ciências por meio de uma linguagem universal [...] o projeto de Popper era fazer a lógica, não a ciência anterior, mas a lógica da descoberta cientifica [...] outro ponto no qual as duas filosofias divergem profundamente é aquele segundo o qual, para Popper, o não científico não é nem absurdo nem, sobretudo, negligenciável e insignificante para a ciência.

Desse modo, podemos dizer que há dificuldades em considerar Popper um antipositivista (cf.: Oliveira 2012). A amplitude de suas obras nos impede de reduzir sua contribuição a rótulos, podemos, contudo, reafirmar que, para ele, o conhecimento científico é sempre falível. É exatamente isto que o princípio de falseabilidade demarca em primeiro lugar, porém, a reboque, acaba por operar uma separação entre teorias científicas e pseudocientíficas.

Para tanto, Popper sugere que a construção de teorias científicas se apoie não mais na lógica indutiva, cujo problema ele afirma ter resolvido, mas na lógica dedutiva, em razão da assimetria lógica que descobre entre indução e dedução: enquanto, na indução, muitos casos particulares não conseguem provar a verdade de uma teoria, na dedução um só caso consegue provar sua falsidade Popper sustenta, então, que o que distingue a racionalidade científica é a atitude crítica, mais preocupada com a busca da verdade do que com a defesa de teorias que possam eventualmente ocultá-la ou dela se afastar [...]. Seu racionalismo crítico, como ficou conhecido o núcleo de seu pensamento, coloca-se frontalmente contra algumas das principais construções teóricas de seu tempo, sobretudo a Psicanálise de Freud, a Psicologia Individual de Adler, a Escola de Frankfurt, sobretudo Adorno e Habermas, o Marxismo e o Positivismo Lógico (Oliveira 2012:10-11).

Pois que, Popper coloca-se, declaradamente, na posição de defensor da unicidade metodológica para todas as ciências. Apesar de ter modificado sua tese ao longo do tempo (Oliveira 2012:231-251), são as primeiras ideias do autor que trouxeram maior impacto na comunidade científica. Nelas, Popper arrazoa que a objetividade científica pode ser interpretada como método. A intersubjetividade nega a subjetividade, percebida como uma interpretação dos fatos por meio de sentimentos de certeza ou incerteza, de crença ou dúvida, asserções ou conjecturas; ou 
seja, a intersubjetividade objetiva é indicada por um controle racional mútuo por via da discussão crítica. E acrescenta: "Manifesto a fé que tenho numa interpretação objetiva, acima de tudo por acreditar, que somente uma teoria objetiva está apta a explicar a aplicação dos cálculos de probabilidades em ciência empírica" (Popper 2007[1934]:164).

Desse modo, ao se debruçar, exclusivamente, sobre o racionalismo crítico, entendemos que Popper não oferecia um quadro que abarcasse as especificidades das outras ciências, como as Ciências Sociais e as Humanidades. Advogamos, assim, corroborando a perspectiva bordieusiana, que um paradigma não pode monopolizar, sozinho, toda complexidade do saber/fazer científico. Portanto, aceitamos, citando Chizzotti (2003:228),

a contestação do modelo único de pesquisa, a crítica à hegemonia dos pressupostos experimentais, ao absolutismo da mensuração e á cristalização das pesquisas sociais em um modelo determinista, causal e hipotético dedutivo: adensam-se as críticas aos pressupostos ontológicos, epistemológicos e metodológicos do modelo convencional, reconhecendo-se a relevância do sujeito, dos valores dos significados e intenções da pesquisa, afirmando a interdependência entre a teoria e a prática, a importância da invenção criadora, do contexto dos dados e da inclusão da voz dos atores sociais.

A própria atividade científica se expande por meio da compreensão de que a experiência humana não pode ser reduzida a um único método de investigação. Certamente isso não significa o descompromisso e a falta de legitimidade e validade das pesquisas, mas, como nos ensina Cartwright (1983:230), "não há razão óbvia para esperar que a mesma alternativa se aplique a toda a disciplina científica".

Pierre Bourdieu, então, em sua reflexão sobre o fazer do sociólogo e o fazer do cientista, nos permite um ponto de partida que não é único, nem positivo, pois não há uma forma de pensamento que possa ser ajustada em uma tipologia hermética. Por essa razão, ele sustenta que é preciso pensar relacionalmente. Nas suas palavras, “[...] deformando a expressão de Hegel: o real é relacional” (Bourdieu 2002:28). Com esse modo de criar inteligibilidade sobre o mundo, ele visa, sobremaneira, "[...] evitar as aparências da cientificidade, contradizer mesmo as normas em vigor e desafiar os critérios correntes do rigor científico" (Bourdieu 2002:42). 
Isso porque, de acordo com Bourdieu (2004), o campo científico é um mundo social e, como tal, faz imposições e solicitações de seus agentes para que as forças centrípetas que regem os temas, objetos e métodos de pesquisa num dado saber sejam conservadas. De tal maneira, os agentes são passivamente conduzidos pelas leis imanentes do campo e passam a reproduzir essas disposições adquiridas, ou seja, o habitus $^{2}$, assegurando a perpetuação da ortodoxia contra a inovação. Eles são levados a um servilismo interessado, pois, com o intuito de barganhar capital científico, acabam por reproduzir uma definição de ciência segundo a qual a realização mais perfeita consiste em fazer aquilo que historicamente já vinha sendo feito. Assim, o autor arrazoa que

o interesse apaixonado que os pesquisadores em ciências sociais têm pelas ciências da natureza não poderia ser compreendido de outro modo: é a definição dos princípios de avaliação de sua própria prática que está em jogo na pretensão de impor, em nome da epistemologia ou da sociologia da ciência, a definição legítima da forma mais legítima de ciência - a ciência da natureza (Bourdieu 1983:8-9).

Pois que, com sua concepção relacional do conhecimento, ele critica que o paradigma empirista possa ser uma representação fixa da verdade científica. Notadamente porque, segundo bem pontuaram Camargo e Elesbão (2004), se nas ciências da natureza o objeto de estudo é uma realidade dada, exterior ao homem, e, assim, capaz de ser apreendida pelo método experimental; já nas ciências humanas e sociais o objeto de estudo é o próprio homem, vivendo em sociedade, ou seja, o homem nas suas relações com os outros homens e com a própria natureza, o que cria toda uma discussão quanto ao seu emprego e sua validade.

Por esse motivo, conforme afirma Scartezini (2010/2011:29-30), o pesquisador

não deve recusar nenhuma construção teórica ou metodológica que possa lhe servir para compreender seu objeto. Assim, não é cabível haver dissociação entre método e prática, pois é errôneo falarmos em algum método separado do objeto de pesquisa, algum método que se encaixe a priori neste objeto e que não necessite ser complementado por outras correntes metodológicas.

2. Uma discussão sobre a noção de habitus e sua relação entre o condicionamento da ação social e as possibilidades de ação do indivíduo, pode ser encontrada em Bronckart e Schurmans (2001). 
Não deve haver uma cristalização das construções científicas, especialmente porque, conforme Bourdieu (2004:35), “a inovação científica não ocorre sem rupturas sociais com os pressupostos em vigor”. Há de se colocar a ciência a serviço da ciência e do progresso desta, pois

[...] a pesquisa é uma coisa demasiado séria e demasiado difícil para se poder tomar a liberdade de confundir a rigidez, que é o contrário da inteligência e da invenção, com o rigor, e se ficar privado deste ou daquele recurso entre os vários que podem ser oferecidos pelo conjunto das tradições intelectuais da disciplina - e das disciplinas vizinhas: etnologia, economia, história. Apetecia-me dizer: "É proibido proibir" ou "Livrai-vos dos cães de guarda metodológicos" (Bourdieu 2002:26).

Adotando a posição apresentada por Bourdieu (1983, 2002, 2004), nas linhas seguintes, iremos defender que a noção de ciência que subjaz ao quadro teórico-metodológico do ISD está pautada numa metodologia relacional, que se distende para a forma como são realizadas as pesquisas aplicadas sobre o estudo da linguagem que se filiam a esse aporte.

\section{A concepção de ciência que subjaz ao quadro geral do ISD}

Convém sublinhar, enquanto base de nossa discussão nessa seção, que ao longo da história da ciência, conforme alvitra Bronckart (2006:233),

desenvolveu-se o pensamento de que o procedimento propriamente científico deveria necessariamente implicar a seleção de domínios restritos de investigação, uma coleta de dados tendendo para uma validade geral e uma organização desses dados no quadro de mundos formais do saber, organização essa que deveria estar submetida ao regime de uma lógica descontextualizada.

Anulando, então, essa forma estigmatizada e única de construção do conhecimento e resgatando o interesse científico pelas dimensões ativas e intervencionistas das condutas humanas, o ISD "se opõe radicalmente a três princípios básicos da tradição filosófico-científica que continuam a orientar a maioria das abordagens das Ciências Naturais 
e das Ciências Humanas/Sociais" (Bronckart 2006:126), a saber: o primeiro é o da estabilidade e finitude dos mecanismos de organização do universo; o segundo é o do recorte dos objetos de conhecimento; e o terceiro, e último, é o do dualismo entre os fenômenos físicos e psíquicos humanos.

Essa postura transgressora e oposicionista, per si, já se alinha à perspectiva relacional de Bourdieu (2002) por romper ou por questionar a tradição na construção do saber científico, de forma a adequar, peculiarmente, as ideias que constituem a orientação geral do projeto interacionista sociodiscursivo. Como uma força centrífuga, então, a proposta teórica do ISD vai de encontro a algumas proposições cristalizadas, ao longo do tempo, sobre a forma de se fazer ciência e de se construir o conhecimento verdadeiro.

Negando a estabilidade e finitude dos mecanismos de organização do universo, princípio formulado, sobretudo pela física newtoniana, o ISD privilegia o estado dinâmico e imprevisível da evolução. A noção de espaço e tempo absolutos, de movimento como mero deslocamento, é corrompida pela ideia de que a realidade é resultado de um processo histórico. O homem é um organismo vivo que revela capacidades novas que foram construídas no curso da evolução.

Enfocando, pois, a historicidade do ser humano, o ISD destaca as - e se interessa por - condições que sob as quais, na espécie humana, se desenvolveram formas particulares de organização social e de interação semiótica, transformando-os em pessoas capazes de colaborar umas com as outras na construção da circunstancialidade que as envolve (Bronckart 1999). Dessa forma, entende que o processo de evolução dotou o homem de capacidades comportamentais particulares, permitindo-o desenvolver capacidades auto-reflexivas e criar instrumentos mediadores de sua relação com o meio, o que se estabeleceu, fundamentalmente, pelo uso da linguagem.

Nesse sentido, a língua só pode ser concebida como produto da interação social, oriunda de uma negociação coletiva que se coloca, perpetuamente sob a dependência desse uso e, portanto, com significações sempre moventes. Por essa razão, ela só pode ser abordada em sua situacionalidade contextual, o que, efetivamente, contraria qual- 
quer possibilidade de homogeneidade e de universalização, tal como proposto pela atitude dominante do saber/fazer científico.

Quanto ao recorte dos objetos do conhecimento, ou seja, à premissa de que para estudar um fenômeno basta compreender suas partes - de modo a poder prever os fenômenos e melhor controlá-los-, o ISD refuta a ideia de se estudar a estrutura interna da linguagem, a língua pela sua menor parte, ou seja, o signo linguístico, conforme proposta saussureana. No cerne dos primórdios da ciência, segundo Bronckart (2008:69),

esse foi o objetivo de Platão no Crátilo, que visava a estabelecer o caráter "natural" das palavras, o de Aristóteles, no Organon, em que afirma que as proposições verbais são fiéis mensageiras das estruturas lógicas do mundo, e também o objetivo da Gramática geral e razoada de Port-Royal, que defendia a ideia de que há estruturas linguageiras universais que se baseiam nas operações de julgamento e de raciocínio humano. Nessa tradição, a linguagem é sempre considerada como um mecanismo secundário, de tradução de estruturas "outras" que a determinariam.

Não se trata, pois, de continuar a conceber a língua como um sistema homogêneo, um acervo imutável depositado na memória coletiva, mas num funcionamento profundamente interdependente do tipo de contexto em que ocorre, dando conta do caráter integral da conduta comunicativa.

Para a compreensão da complexidade da linguagem, o ISD irá preconizar a interdependência entre as diferentes dimensões humanas (fisiológica, cognitiva, afetiva, linguística, social). Contesta, portanto, a divisão atual das Ciências Humanas/Sociais em defesa de uma ciência do humano (Bronckart 2006; 2009). Sendo assim, se apresenta como uma corrente multidisciplinar que recebe influência da Psicologia, da Linguística, da Filosofia, da Sociologia, da Pedagogia e que se coloca acessível ao diálogo acadêmico com outras disciplinas, visando a problematização global de um dado objeto de estudo, conforme, por exemplo, pode ser constatado em Bronckart (2009) quando propõe a integração das contribuições de Voloshinov, Vygotsky e Saussure na constituição do quadro Interacionista Sociodiscursivo.

Isso significa que não aborda os fatos de maneira departamentalizada, mas atravessados e sob a dependência dos diversos saberes. Para 
além do experimentalismo, de uma análise simplificada e arbitrária, a abordagem interacionista sociodiscursiva privilegia a multidimensionalidade da situação concreta nos estudos da linguagem. Com isso, preconiza um modelo de análise textual "descendente" (Bronckart 2009), que se adapta ao dinamismo das interações. Nessa acepção, segundo Bronckart (1999), o texto é entendido como entidade genérica que está em relação de interdependência com as propriedades do contexto em que é produzido, ou seja, resulta de parâmetros múltiplos, a exemplo: da situação real de comunicação, dos modelos de gênero, dos tipos discursivos, das regras do sistema da língua, das decisões particulares do autor etc.

Logo, o procedimento metodológico bronckartiano centra-se nas condições sociopsicológicas de produção textual, mas, também, na análise das propriedades estruturais e funcionais internas (léxico-sintática, semântica e paralinguística). Para tanto, essa descrição não acontece, tão-somente, na ordem quantitativa das propriedades linguísticas, mas, especialmente, nas configurações qualitativas-interpretativista dos mecanismos abordados. Essa abordagem qualitativa-interpretativista exige o protagonismo conjunto do pesquisador com o que está sendo investigado, refutando-se a proposição objetivista, defendida por Popper (2007 [1934]), de que, para se fazer ciência, há de existir o distanciamento do pesquisador com a realidade observada, isto é, de que "quando o pesquisador encontra-se implicado na situação que observa, a constituição de dados de um mundo formal do saber se torna impossível” (Bronckart 2006:236).

No fio desse construto, contrapondo-se ao terceiro princípio da tradição filosófico-científica: o dualismo mente-corpo, o ISD assume uma posição monista (Bronckart et al. 1996; Bronckart 1999), que busca compreender a diversidade do ser humano e de todas as coisas através de um arranjo unicista. Para tanto, rejeita que os objetos e os corpos estejam inscritos numa dimensão material, enquanto que as ideias e sentimentos estão inscritos numa dimensão psíquica. É importante frisar que isso implica, ao mesmo tempo, renunciar, também, ao monismo materialista, que arrazoa que toda existência se reduz à matéria e seus atributos orgânicos e biológicos; e ao monismo idealista, que se fundamenta nos princípios formativos de natureza imaterial, fazendo abstração das dimensões comportamentais do desenvolvimento humano. 
Portanto, no ISD, o físico e o psíquico são duas propriedades de uma mesma matéria homogênea, que não implica cisões. De modo geral, então, o sujeito passa a ser compreendido em sua heterogeneidade e fluidez (não apenas como sujeito físico-empírico, de existência individualizada no mundo), tornando impossível basear os estudos em relações de causa e efeito, ante a complexidade das práticas em que está inserido.

Diante do exposto, ratificamos nosso entendimento de que o paradigma empirista - assim como nenhum outro - seja um padrão para o saber/fazer científico. Isso porque, há uma relatividade situacional, conforme formulações de Bourdieu (2002), que exige o abandono de uma autoridade única em favor da pluralidade teórico-metodológica. O que não significa, citando Chizzotti (2003:232), que aqueles que se decidiram pela descoberta de novas vias investigativas tenham, ao mesmo tempo, pretendido "furtar-se ao rigor e à objetividade, mas reconhecem que a experiência humana não pode ser confinada aos métodos nomotéticos de analisá-la e descrevê-la".

Assim, reconhecendo a relevância do sujeito e afirmando a dependência recíproca entre a teoria e a prática, as pesquisas realizadas no âmbito do ISD, enquanto campo aplicado dos estudos da linguagem, refletem certa versatilidade uma vez que buscam encontrar significados patentes para o seu objeto, bem como os significados que as pessoas dão a ele. Para isso, servem-se de recursos como a entrevista, o estudo de caso, a observação participante, a etnografia, a pesquisa-ação, dentre outros, apresentando, do mesmo modo, de forma inovadora os resultados das investigações, criando um excitante universo de possibilidades que fogem ao convencionalmente instituído pelas Ciências da Natureza. Precisamos "ter em mente que as ciências humanas/sociais são diferenciadas pelo nível em que abordam os objetos que lhes são comuns" (Bronckart et al. 1996:72).

Nessa direção, conforme refere Günther (2006), essas pesquisas evidenciam um conjunto de métodos e técnicas, adaptados ao caso específico, em detrimento de um método padronizado único. Elas ressaltam, assim, que é o método quem deve se adequar ao objeto de estudo. Sobre isso, Bronckart et al. (1996) surpreendem-se ao reconhecer que as sucessivas "revoluções epistemológicas" foram desenvolvidas em perfeita continuidade metodológica. 
Ao empreender a analogia de que o processo de pesquisa pode ser concebido como um mosaico, que descreve um fenômeno complexo a ser compreendido, Günther (2006:202) infere que, nesse sentido,

é fácil entender que as peças individuais representam um espectro de métodos e técnicas, que precisam estar abertas a novas ideias, perguntas e dados. Ao mesmo tempo, a diversidade de peças desse mosaico inclui perguntas fechadas e abertas, implica em passos predeterminados e abertos, utiliza procedimentos qualitativos e quantitativos.

Como ponto comum, ao abordar as ações de linguagem humanas, essas pesquisas se interrogam sobre as condições sociohistóricas de elaboração dos conhecimentos científicos, considerando a diversidade de seu conteúdo e de seu estatuto, relacionando, principalmente com a diversidade de culturas e sociedades humanas.

Imbuídos dessa concepção empirista de compreender o fazer científico, alguns, inapropriadamente, conforme refere Chizzotti (2003:223), percebem essa forma de produzir conhecimento como "leve (soft), realizada no convívio com pessoas e fatos, oposta às ciências que se autodenominam duras (hard), realizadas na impessoalidade dos dados, nas clausuras laboratoriais ou em laboriosas exegeses estatísticas". Julgamos, entretanto, que não se trata de uma relação antagonista entre o simples versuso complexo ou o híbrido versus o puro, mas de perspectivas relacionais de criar inteligibilidade sobre a realidade.

Esse olhar, todavia, não é exclusivo da corrente interacionista sociodiscursiva. Com o advento da Pós-Modernidade, no final do século $\mathrm{XX}$, a ciência tem sido questionada em vários de seus princípios (Araújo 2006). Estamos vivenciando uma crise do modelo dominante, de modo que a realidade social tem passado a ser vista como espaço de construção e atribuição de significados, tornando-se o ponto de partida da pesquisa; concomitantemente, as condições objetivas de vida têm assumido significados subjetivos, num apelo à reflexão e à processualidade da investigação (Günther 2006).

À título de ilustração, retomamos aqui os resultados de nossa pesquisa que analisa comparativamente artigos nas áreas de Filosofia e de Psicologia no sentido de investigar a concepção subjacente de ciência materializada nos textos acadêmicos. Nesse sentido, posicio- 
namos a Filosofia no cerne da discussão sobre o discurso científico, em especial, por estar num entre lugar, exatamente no ponto de união e ruptura das reflexões acerca desse tema. Dessa maneira, ao tomar o texto da área da Filosofia para estudo, não estamos tentando reduzi-la ao paradigma cientificista dominante que acaba por instituir o critério de verdade - o que é fato científico e o que não o é, qual metodologia é verdadeiramente científica, quais temas são de interesse para ciência, em detrimento de outros -, mas observá-la como voz importante para compreensão do fenômeno científico a partir de uma visão monista sobre o conhecimento humano e seu papel na formação das atividades sociais (cf.: Basílio, Pereira e Menezes, 2014).

Esse é o deslocamento feito pelo ISD que, distante do modo empirista de construção do conhecimento, fertiliza a originalidade criadora na investigação científica, direcionando uma nova maneira de fazer pesquisa em Ciências Humanas e Sociais e, particularmente, na LA, área a que está amplamente arraigado. Assim, é preciso reconhecer essa postura realmente científica adotada por esse aporte quando reconhece a necessidade de permanentes embates teórico-metodológicos para, assim, fazer avançar o trabalho dos pesquisadores e, por conseguinte, o quadro geral que subjaz às pesquisas. Isso se expande por meio da compreensão de que não existe uma verdade única, absolutista, não havendo de se esperar que a mesma alternativa se aplique a toda realidade. Isso coloca o pesquisador na posição de agente, criador de saberes, não na de um simples executor do saber instituído. Em nosso entendimento, isso, sim, é fonte de transformação e desenvolvimento dos pesquisadores e do saber/fazer científico.

\section{Considerações finais}

Essa reflexão nos leva a considerar que, no processo de construção do conhecimento, o pesquisador, enquanto consumidor de pesquisa, não deve admitir um padrão metodológico dogmático e autoritário. Do contrário, com base na perspectiva relacional bourdieusiana, deve estar aberto às várias abordagens e avaliar, do ponto de vista prático, aquela que melhor se adequa a sua questão de pesquisa. Isso inclui, inclusive, comportar mais de um método, notadamente porque as questões de pesquisa, em geral, são multifacetadas. Como salienta Günther (2006), 
considerando os recursos disponíveis para lidar com uma determinada pergunta científica, coloca-se para o pesquisador a tarefa de encontrar e usar a abordagem que permita chegar a um resultado que melhor contribua para a compreensão do fenômeno e para o avanço do bemestar social. Que fique claro, então, que, nesse sentido, não se trata de fazer sobrepor um novo paradigma, em prejuízo do outro, mas de fazer valer a pluralidade dos métodos.

Compreendemos, a partir da discussão aqui levantada, o papel nuclear do cientista como autor da pesquisa e dos fatos científicos. Incluir o aspecto subjetivo ou esforçar-se para eliminar traços subjetivos do trabalho científico é uma postura subjacente à escolha do método de geração ou coleta de dados, bem como, de análise ou interpretação destes. Esses aspectos podem ser impostos pela época ou pela instituição em que o cientista trabalha como nos ensina Ziman (1979 [1968]), ao chamar a atenção da comunidade acadêmica aos aspectos humanos, sociais, éticos e político-comerciais do trabalho científico. Em todos os casos, porém, o papel do cientista como agente-produtor e o contexto de produção em que ele trabalha afeta e constitui o seu conceito de cientificidade.

Percebemos, assim, que esse é o caminho trilhado pelo ISD desde a construção de seu aporte teórico-metodológico até a realidade prática das pesquisas. Refutando a maneira clássica de compreender o saber/ fazer científico, as construções interacionistas sociodiscursivas privilegiam aquilo que melhor satisfaz às suas necessidades intrínsecas, mesmo que isso signifique romper com o socialmente instituído como "científico". Conquanto isso pareça óbvio, as investigações conduzidas no interior do projeto ATA têm identificado que, nos diversos campos do saber, há um esforço das disciplinas para se coadunar e manter o paradigma empirista dominante como forma de barganhar capital acadêmico e lograr status cientificista.

Com fins específicos, então, sob a égide dos dois eixos de atuação do projeto ATA - 1) análise dos aspectos linguístico-discursivos de textos acadêmicos e 2) didatização da escrita no interior dos diversos campos de produção do conhecimento -, esse estudo contribui para a percepção futura de quais ideologias cientificistas guiam as pesquisas nos diferentes campos do saber e como essas questões encontram-se 
materializadas nos textos escritos. Por outro lado, marca a concepção de ciência que perpassa as próprias discussões do grupo, tendo em vista que o ATA opera à luz do ISD.

De forma mais ampla, esperamos que nossas discussões nesse trabalho subsidiem o campo dos estudos da linguagem, suscitando questionamentos outros, especialmente porque, segundo observa Chizzotti (2003), tem havido um considerável aumento de publicações que discutem questões epistemológicas, metodológicas e técnicas da pesquisa que atestam o interesse crescente por uma temática em franco desenvolvimento.

Recebido em maio de 2015 Aprovado em janeiro de 2016 E-mails: recostamenezes@gmail.com reginacmps@gmail.com raquel.basilio@gmail.com

\section{Referências bibliográficas}

Araúso, Carlos Alberto Ávila. 2006. A ciência como forma de conhecimento. Ciências \& Cognição, v. 08:127-142.

BACON, Francis. 2014 [1620]. Novo órganon. São Paulo: EDIPRO.

Basílio, Raquel; Pereira, Regina Celi Mendes \& Menezes, Renata de Lourdes Costa de. 2014. A escrita acadêmica e o fazer científico: análise do gênero artigo científico. In: Jornada Nacional do Grupo de Estudos Linguísticos do Nordeste - GELNE, 25. 2014, Natal. Anais... Natal: EDUFRN.

Bourdieu, Pierre. 1983. Questões de sociologia. Rio de Janeiro: Marco Zero.

2002. O poder simbólico. 5. ed. Rio de Janeiro: Bertrand Brasil.

2004. Os usos sociais da ciência: por uma sociologia clínica do campo científico. São Paulo: Editora UNESP.

Brandão, Caius. 2010. A revolução científica e a nova visão de mundo do homem moderno. Disponível em: <www.academia.edu/1085626/A_ revolucao_cientifica_e_a_nova_visao_de_mundo_do_homem moderno $>$. Acesso em: 16 de set. 2014.

BRONCKART, Jean-Paul. 1999. Atividade de linguagem, textos e discursos: por um interacionismo sociodiscursivo. São Paulo: EDUC. 
2006. Atividade de linguagem, discurso e desenvolvimento humano. Campinas, SP: Mercado de Letras.

.2008. O agir nos discursos: das concepções teóricas às concepções dos trabalhadores. Campinas, SP: Mercado das Letras.

. 2009. Le langage au coeur du fonctionnement humain. Un essai d'integration des apports de Voloshinov, Vygotski et Saussure. Estudos Linguísticos/Linguistic Studies, Lisboa, n. 3:31-62.

et al. 1996. Manifesto: Reformatando as humanidades e as ciências sociais, uma perspectiva vygostkiana. Revista brasileira de Educação, n. 3:64-74.

; Schurmans, Marie-Noëlle. 2001. Pierre Bourdieu - Jean Piaget: habitus, schèmes et construction du psychologique. In: LAHIRE, Bernard (org.). Le travail sociologique de Pierre Bourdieu. Paris: La Découverte/Syros.

Camargo, José Carlos Godoy \& Elesbão, Ivo. 2004. O problema do método nas ciências humanas: o caso da Geografia. Mercator, ano 3, n. 6:7-18.

Cartwright, Nancy. 1983. How the Laws of Physics Lie. Oxford: Clarendon Press.

Chalmers, Alan Francis. 1993. O que é ciência, afinal? São Paulo: Editora Brasiliense.

Chizzotтi, Antonio. 2003. A pesquisa qualitativa em ciências humanas e sociais: evolução e desafios. Revista Portuguesa de Educação, Portugal, v. 16, n. 02:221-236.

GÜNTHER, Hartmut. 2006. Pesquisa qualitativa versus pesquisa quantitativa: esta é a questão? Psicologia: Teoria e Pesquisa, v. 22, n. 2:201206.

Lacerda, Gustavo Biscaia de. 2009. Augusto Comte e o "positivismo" redescobertos. Rev. Sociol. Polit., Curitiba, v. 17, n. 34:319-343.

Oliveira, Paulo Eduardo de (org.). 2012. Ensaios sobre o pensamento de Karl Popper. Curitiba: Círculo de Estudos Bandeirantes.

Popper, Karl. 2007 [1934]. A lógica da pesquisa cientifica. São Paulo: Cultrix.

Quelbani, Mélika. 2009 [1953].O Círculo de Viena. São Paulo: Parábola.

SCARTEZINI, Natalia. 2010/2011. Introdução ao método de Pierre Bourdieu. Cadernos de Campo, n. 14/15:25-37.

SCRUTON, Roger. 2008. Uma breve história da filosofia moderna. Rio de Janeiro: José Olympio.

Ziman, John. 1979 [1968]. Conhecimento público: a dimensão social da ciência. São Paulo: Edusp. 
